\title{
Winter sea-ice mapping from multi-parameter synthetic-aperture radar data
}

\author{
ERIC RignOt AND MARK R. DRINKWATER \\ Jet Propulsion Laboratory, California Institute of Technology, Pasadena, California 91109, U.S.A.
}

\begin{abstract}
The limitations of current and immediate future single-frequency, single-polarization, space-borne SARs for winter sea-ice mapping are quantitatively examined, and improvements are suggested by combining frequencies and polarizations. Ice-type maps are generated using multi-channel, air-borne SAR observations of winter sea ice in the Beaufort Sea to identify six ice conditions: (1) multi-year sea ice; (2) compressed first-year ice; (3) first-year rubble and ridges; (4) first-year rough ice; (5) first-year smooth ice; and (6) first-year thin ice. At a single polarization, C- $(\lambda=5.6 \mathrm{~cm})$ and L- $(\lambda=24 \mathrm{~cm})$ band frequencies yield a classification accuracy of 67 and $71 \%$, because C-band confuses multi-year ice and compressed, rough, thick first-year ice surrounding multi-year ice floes, and L-band confuses multi-year ice and deformed first-year ice. Combining C- and L-band improves classification accuracy by $20 \%$. Adding a second polarization at one frequency only improves classification accuracy by $10-14 \%$ and separates thin ice and calm open water. Under similar winter-ice conditions, ERS- $1\left(C_{\mathrm{VV}}\right)$ and Radarsat $\left(C_{\mathrm{HH}}\right)$ would overestimate the multi-year ice fraction by $15 \%$ but correctly map the spatial variability of ice thickness; J-ERS-1 $\left(L_{\mathrm{HH}}\right)$ would perform poorly; and J-ERS-1 combined with ERS-1 or Radarsat would yield reliable estimates of the old, thick, first-year and thin-ice fractions, and of the spatial distribution of ridges. With two polarizations, future single-frequency space-borne SARs could improve our current capability to discriminate thinner ice types.
\end{abstract}

\section{INTRODUGTION}

Sea ice is an important modulator of regional and global climate because of the insulating layer which it forms between the cold polar air masses and the relatively warm oceans beneath the ice. To understand the feed-backs between sea-ice and climate change, extensive satellite observations of the sea-ice extent and variability are necessary over long periods of time (Carsey and others, 1992). Satellite sensors operating at visible and nearinfrared optical wavelengths (e.g. Landsat and the Advanced Very High Resolution Radiometer) have made and will continue to make significant contributions to sea-ice surveillance (Massom, 1991) but are limited by weather and light conditions. Space-borne microwave radiometers have been designed and flown in the past two decades to overcome these limitations. Considerable work has been done to develop a capability for extracting seaice geophysical information from these data (Steffen and others, 1992) but comparisons with other estimates (Rothrock, 1992) or results from other remote-sensing instruments (Cavalieri, 1992) have shown that improvements are still needed to resolve ambiguities in ice types, and regional and global ice-concentration estimates. Despite a narrower swath and a higher cost, spaceborne, active, synthetic-aperture, microwave systems may be a solution of the future for monitoring ice conditions in the polar Arctic at microwave frequencies. In contrast to passive microwave satellites, that are limited to observa- tions at the scale of several tens of kilometers, SAR systems resolve ice-type variability, ice-deformation features and ice kinematics at the scale of several tens of meters.

Since mid-1991, two single-frequency, single-polarization, space-borne SAR instruments have been launched to be joined by several others before the end of the decade. These instruments provide the first calibrated, continuous, data set of SAR observations of the polar regions available on a long-term basis. Operational systems have been developed to accommodate the processing, archiving and distribution of the enormous volume of data generated by these instruments, and for generating SAR geophysical products. For instance, icemotion maps are generated at the Alaska SAR Facility (ASF), in Fairbanks, Alaska, using C-band $(\lambda=5.7 \mathrm{~cm})$, VV-polarization (vertical transmit and receive) spaceborne, SAR data from the European Remote Sensing Satellite, ERS-1 (Attema, 1991). Similarly, ice-type and ice-concentration maps are generated at ASF using ERS-1 SAR data (Kwok and others, 1992). The iceclassification software separates multi-year ice, first-year ice and new ice/open water (at the system noise-power level) based on their radar back-scatter characteristics. The spatial variability of the distribution of these three ice types is used as a proxy indicator of the regional variability of ice thickness, a required parameter for estimating the dynamic and thermodynamic balance of the polar regions. In the near future, the ice-classification 
software will be extended to the L-band HH-polarization (horizontal transmit and receive) data from the Japanese Earth Resources Satellite, J-ERS-1 (Nemoto and others, 1991), and the C-band HH-polarization data from Radarsat (Raney and others, 1991). Evaluating the limitations of these single-channel SAR instruments for sea-ice-type mapping is an active area of research but the validation process will be long and difficult because it requires routine $\mathrm{SAR}$ observations and correlative data from many other sensors.

Most recently, a new radar technology has been developed to make SAR measurements at more than one frequency and/or one polarization. Numerous radar signature-modeling studies (Winebrenner and others, 1992), in-situ surface observations (Onstott, 1992) and controlled experiments (Bredow and others, 1989) have indicated that multi-channel SAR systems could improve our current capability to identify different ice conditions and permit the retrieval of geophysical parameters of importance such as snow-cover characteristics, ice salinity and thickness of new ice directly from the microwave ice signatures. The first examples of multi-frequency, polarimetric, SAR observations of sea ice were acquired in March 1988 by the NASA/Jet Propulsion Laboratory aircraft SAR (AIRSAR) over the Beaufort, Chukchi and Bering Seas (Drinkwater and others, 1991). The initial results confirmed that multi-parameter SAR data resolve different sub-categories of first-year sea ice better than single-channel instruments (Drinkwater and others, 1992). In this study, we present a more complete and quantitative evaluation of the performance level of various frequencies and polarizations, and combinations of both, for winter-ice mapping and for estimating ice fractions. Ice maps generated using multi-parameter SAR data and validated using a combination of ancillary information are used as a yardstick to determine the limitations of single-channel satellite SARs for winter-ice mapping and to determine whether combinations of frequencies and polarizations could overcome these current limitations. The analysis is based on the identification of six winter-ice conditions: (1) multi-year (MY) sea ice; (2) compressed first-year (CFY) sea ice; (3) first-year rubble and ice ridges (FYRR); (4) first-year rough ice (FYR); (5) first-year smooth ice (FYS); and (6) thin first-year ice (ThI). Open water is absent from all analyzed data but is included in the discussion because of its important influence on energy fluxes between ocean and atmosphere.

\section{AIRSAR DATA SET}

AIRSAR acquired SAR observations of sea-ice in March 1988 over the Beaufort Sea, north of Alaska, at C- $(\lambda=5.6 \mathrm{~cm})$, L- $(\lambda=24 \mathrm{~cm})$ and P- $(\lambda=68 \mathrm{~cm})$ band frequencies. At each frequency, the complete scattering matrix (van der Hulst, 1981; Ulaby and Elachi, 1990) of each resolution element is recorded and the data are processed such that the scattering matrices acquired at different frequencies are spatially registered. A scattering matrix comprises four complex numbers $S_{\mathrm{HH}}, S_{\mathrm{HV}}, S_{\mathrm{VH}}$, and $S_{\mathrm{VV}}$, where $S_{\mathrm{VH}}$ is a complex-number representation of the amplitude and phase of the radar return received at
$\mathrm{V}$-polarization when $\mathrm{H}$-polarization is transmitted. Subsequent SAR processing yields SAR data in Stokes format (Ulaby and Elachi, 1990) or equivalently in crossproduct format, i.e. for each pixel element the crossproducts $\left\langle S_{X Y} S_{X^{\prime} Y^{\prime}}\right\rangle$ are stored, where $X, Y, X^{\prime}$ and $Y^{\prime}$ are $\mathrm{H}$ or $\mathrm{V}$, an asterisk denotes complex conjugation and \langle\rangle indicates a spatial-averaging process over several (four in practice) contiguous elements called multi-look processing in the SAR literature. Although there are 16 cross-products for each pixel element, a number of them are of second-order magnitude for a large variety of natural targets (Borgeaud and others, 1987; Nghiem and others, 1992), leaving only four cross-products for complete characterization of the polarimetric characteristics of a natural target at each frequency or equivalently the following five real numbers

$$
\begin{aligned}
\sigma_{\mathrm{HH}} & =\left\langle S_{\mathrm{HH}} S_{\mathrm{HH}}^{*}\right\rangle ; \\
\sigma_{\mathrm{HV}} & =\left\langle S_{\mathrm{HV}} S_{\mathrm{HV}}^{*}\right\rangle ; \\
\sigma_{\mathrm{VV}} & =\left\langle S_{\mathrm{VV}} S_{\mathrm{VV}}^{*}\right\rangle, \\
\rho_{\mathrm{HHVV}} & =\frac{\left|\left\langle S_{\mathrm{HH}} S_{\mathrm{VV}}^{*}\right\rangle\right|}{\sqrt{\left\langle S_{\mathrm{HH}} S_{\mathrm{HH}}^{*}\right\rangle} \sqrt{\left\langle S_{\mathrm{VV}} S_{\mathrm{VV}}^{*}\right\rangle}} ; \\
\phi_{\mathrm{HHVV}^{*}} & =L\left(\left\langle S_{\mathrm{HH}} S_{\mathrm{VV}}^{*}\right\rangle\right)
\end{aligned}
$$

where $L(x)$ denotes the phase of the complex number $x$. The radar back-scatters $\sigma$ s are normalized (by the projected area of a pixel element) intensities, expressed in decibels $(\mathrm{dB})$ by taking ten times the base 10 logarithm of their magnitude. Note that the polarimetric dimension, $\phi_{\mathrm{HHVV}^{*}}$, is present in the last two terms of Equation (1).

A total of ten scenes from the Beaufort Sea was processed at $12 \mathrm{~m}$ resolution in cross-product format but we limit the present analysis to two scenes, acquired at different dates and locations, that are representative of typical ice conditions in the Beaufort Sea in March 1988, and for which we have sufficient ancillary information for validating the ice-type labels. The two scenes were acquired in a transition zone between the extensive near-shore first-year ice region and the multi-year polar ice pack to the north. Image 1372 was acquired at a center location of $73^{\circ} 2.9^{\prime} \mathrm{N}, 142^{\circ} 17.1^{\prime} \mathrm{W}$ at $171955 \mathrm{~h}$ GMT on 11 March 1988 and is shown in Figure 1a at C-band VV-polarization and in Figure $1 \mathrm{~b}$ at L-band $\mathrm{HH}$ polarization. Near range is on top, with the aircraft flying from right to left, looking to its left, and heading north. Pixel spacing is $6.7 \mathrm{~m}$ in range by $12.1 \mathrm{~m}$ in azimuth. The scene is $12 \mathrm{~km}$ by $8 \mathrm{~km}$ in size on the ground and the incidence angle $\theta_{\mathrm{i}}$ of the radar illumination on to the surface varies between $29.3^{\circ}$ and $52.4^{\circ}$ from top to bottom. Image 1372 is one of the few scenes acquired in the Beaufort Sea in March 1988 where thin ice could be identified in a recently frozen lead. Image 311 , shown in Figure $2 \mathrm{a}$ at C-band VV-polarization and in Figure $2 \mathrm{~b}$ at L-band HH-polarization, was acquired at a center location of $72^{\circ} 38.2^{\prime} \mathrm{N}, 143^{\circ} 48.1^{\prime} \mathrm{W}$ at $043508 \mathrm{GMT}$ on 19 March 1988. $\theta_{\mathrm{i}}$ varies between $19.8^{\circ}$ and $50.2^{\circ}$ across range. The buildings of the Applied Physics Laboratory (APL) drifting ice station (APLIS'88) (Wen and -others, 1989) appear as a bright-point target at the edge of a less bright multi-year ice floe (Fig. 2a).

An accurate radiometric and polarimetric calibration of the SAR data is not necessary for segmenting and 
a
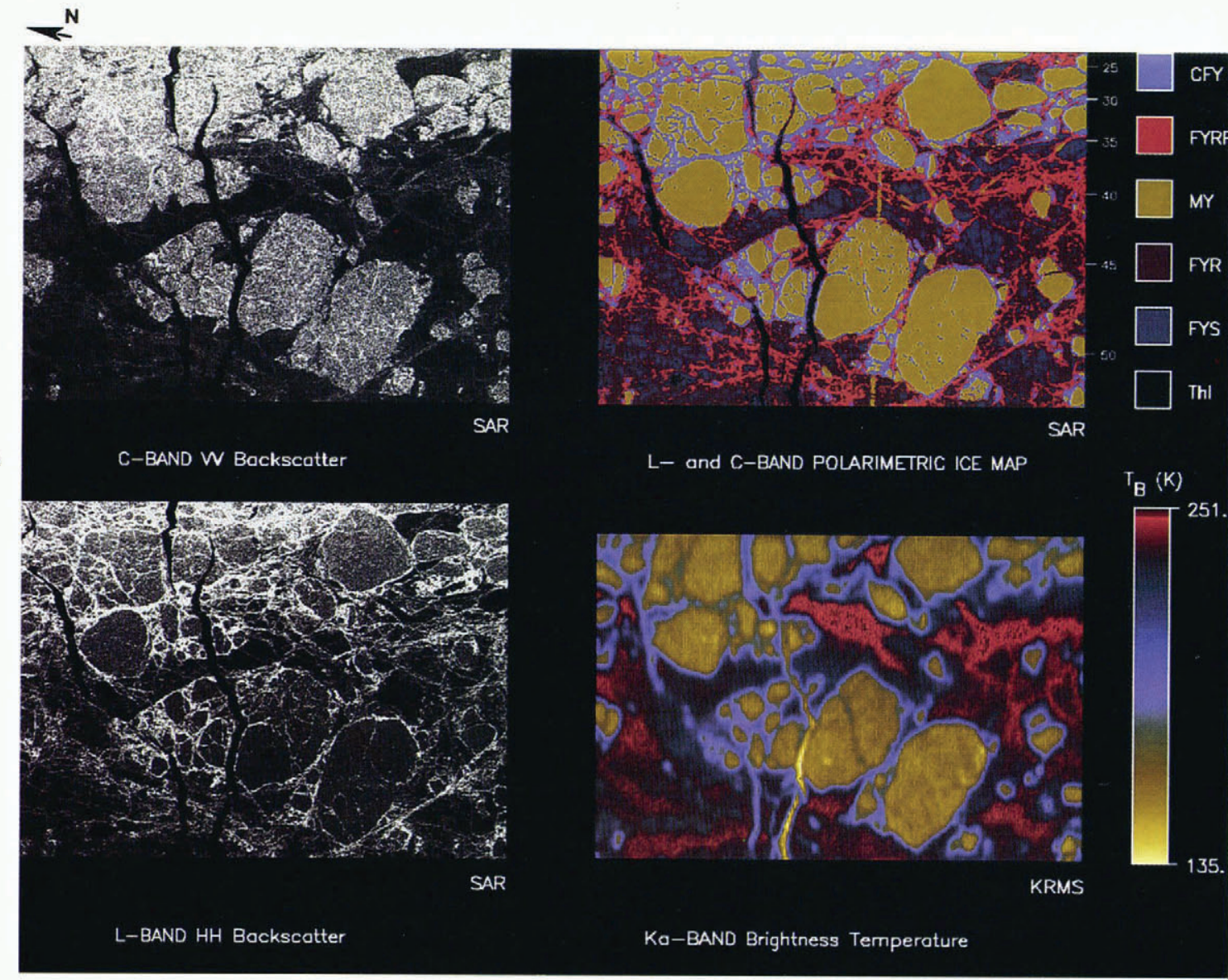

Fig. 1. SAR-amplitude image of sea ice in the Beaufort Sea, Alaska, acquired by AIRSAR at a center location of $73^{\circ} 2.9^{\prime} \mathrm{N}, 142^{\circ} 17.1^{\prime} \mathrm{W}$ at $171955 \mathrm{~h}$ GMT on 11 March 1988 (image 1372) at (a) C-band frequency, VVpolarization; (b) L-band frequency, $H H$-polarization; (c) MAP classification of $L$ - and C-band fully polarimetric $S A R$ data into six ice types; (d) Brightness temperature $T_{\mathrm{B}}$ from $\mathcal{N O R D A} K_{\mathrm{a}}$-band radiometer microwave system.

classifying SAR data but it is required for correct physical analysis of the extracted microwave signatures. Calibration of the phase difference $\phi_{\mathrm{HHVV}^{*}}$, and cross-talk removal between the $\mathrm{H}$ - and $\mathrm{V}$-polarized radar channels (van Zyl, 1990) were performed for both scenes assuming that multi-year sea ice is an azimuthally asymmetric random medium (Nghiem and others, 1992) as the hummocky topography of multi-year sea ice and its airbubble inclusions do not show any azimuthal preference (Weeks and Ackley, 1982). The gain imbalance between the $\mathrm{H}$ - and V-polarized radar channels was determined to be accurate to within $1 \mathrm{~dB}$ at L- and C-band, and $2.5 \mathrm{~dB}$ at P-band from a study of the radar performance during that period (Freeman, 1990). In the absence of external calibration devices deployed in the scene prior to flight, we adjusted the absolute gain of the radar manually to reproduce published scatterometer measurements of multi-year ice under cold and dry conditions. The radar back-scatter $\sigma$ of winter multi-year sea ice is set to $-9 \mathrm{~dB}$ at $23^{\circ}$ for C-band VV-polarization (Kwok and others, 1992), $-15 \mathrm{~dB}$ at $35^{\circ}$ for L-band $\mathrm{HH}$-polarization (Ulaby and others, 1986) and to $-28 \mathrm{~dB}$ at $35^{\circ}$ for P-band HHpolarization (Parashar, 1974). As a result of natural spatial variations in radar back-scatter from multi-year sea ice and temporal variations induced by changing environmental conditions, these reference values have a standard deviation of $2.2 \mathrm{~dB}$ at C-band, $2 \mathrm{~dB}$ at L-band (Kwok and others, 1992; Rignot and Kwok, 1993) and $2 \mathrm{~dB}$ at P-band (Parashar, 1974).

\section{WEATHER AND ICE CONDITIONS}

Weather data were collected within a $150 \mathrm{~km}$ radius at the APLIS88 ice station located approximately $350 \mathrm{~km}$ north of Prudhoe Bay, Alaska, between March and April 1988 (Wen and others, 1989). These data provide the most reliable information about the meteorological conditions in the region where the SAR imagery was acquired. Daily observations of air temperatures, atmospheric pressure and wind direction and speed collected at APLIS'88 are summarized in Figure 3. Air temperatures were below $-10^{\circ} \mathrm{C}$ on $11 \mathrm{March}$, rose to about $-7^{\circ} \mathrm{C}$ and subsequently fell below $-20^{\circ} \mathrm{C}$ on $19 \mathrm{March}$. Wind speeds were usually below $5 \mathrm{~m} \mathrm{~s}^{-1}$. Measurements of the drift speed of the ice station (Wen and others, 1989) revealed rapid ice motion and deformation on 10 March correlated with high wind speeds of 7-8 $\mathrm{m} \mathrm{s}^{-1}$. Sea-ice images of 11 March (Fig. 1) reveal important new cracks and leads in the ice created by divergent ice motion, with leads rapidly freezing under the cold conditions. The newly frozen ice leads remained relatively undeformed, indicating that 

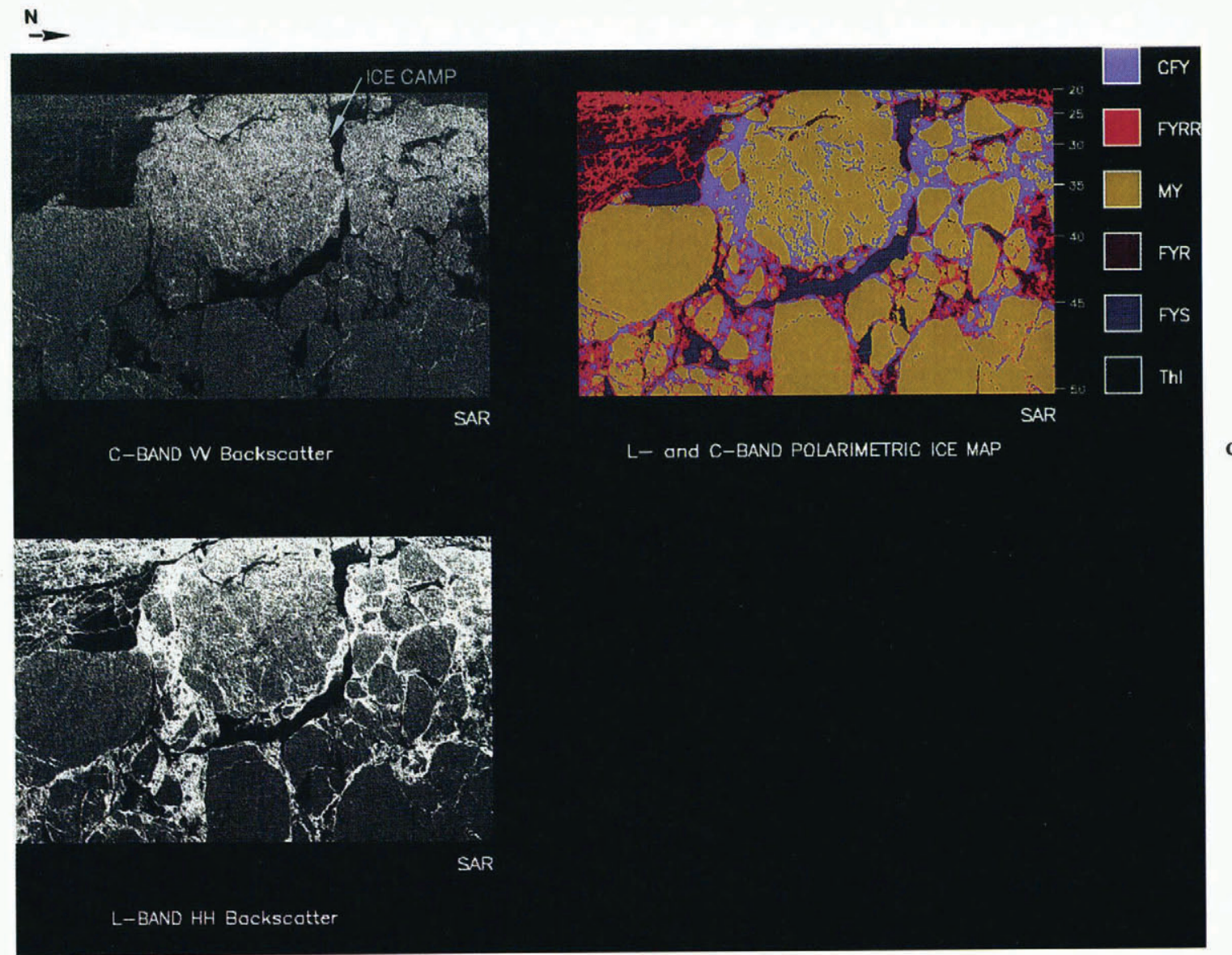

Fig. 2. SAR-amplitude image of sea ice in the Beaufort Sea, Alaska, acquired by AIRSAR at a center location of $72^{\circ} 38.2^{\prime} \mathrm{N}, 143^{\circ} 48.1^{\prime} \mathrm{W}$ at $043508 \mathrm{~h}$ GMT on 19 March 1988 (image 311) at (a) C-band frequency, VVpolarization; (b) L-band frequency, HH-polarization; (c) MAP classification of $L$ - and $C$-band fully polarimetric SAR data into five ice types (no ThI). The APLIS'88 ice camp (bright return) is located at the edge of a multi-year ice floe (darker background).

little convergence was observed after freeze-up. Significant deformation is, however, revealed in first-year ice surrounding the large and rounded multi-year ice floes with the presence of a dense and complex network of rubble fields and ridges over the whole area. Ice conditions at APLIS'88 (Fig. 2) comprised a mixture of first-year ice and multi-year ice floes (Cavalieri and others, 1991). The ice camp was located at the edge of a multi-year ice floe, near a smooth and undeformed refrozen lead which was used to build an aircraft runway. First-year ice in the vicinity of the station was 1.5-2.4 m thick, with a dry-snow cover of variable depth with a mean of $15 \mathrm{~cm}$ and a relatively flat surface. Wen and others (1989) reported that multi-year ice floes were snow-covered and hummocked to amplitudes of $6 \mathrm{~m}$. Pressure ridges and rubble fields fringed the lead near the camp. Immediately north of the lead was a relatively rough rubble field with large ice chunks. An aerial photograph of the ice camp looking north (Fig. 4) shows the boundaries of multi-year ice floes, deformed and

Fig. 3. Daily observations of air temperatures, atmospheric $\quad \triangleright$ pressure and wind direction and speed collected at APLIS'88 between March and April (from Wen and others, 1989).
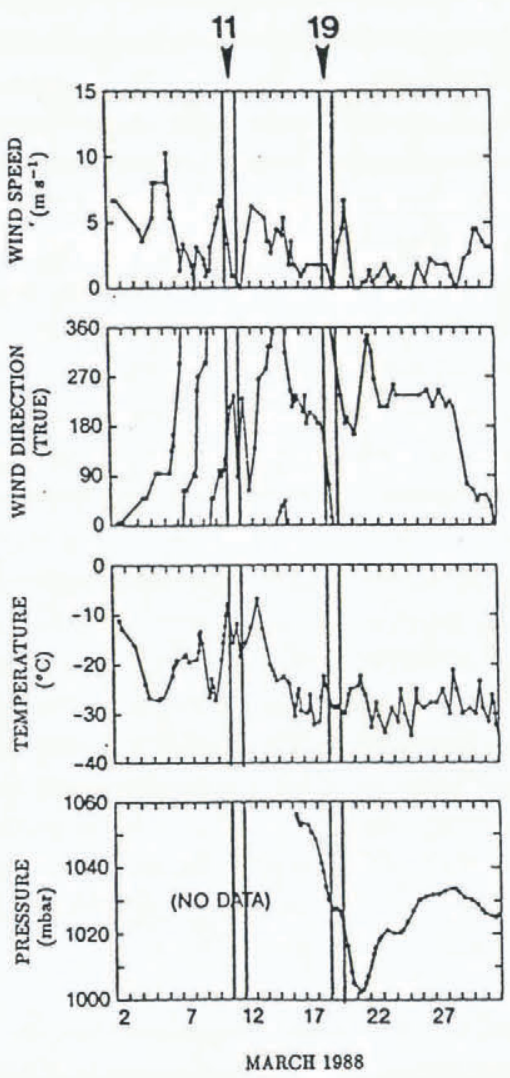
Rignot and Drinkwater: Winter sea-ice mapping from multi-parameter synthetic-aperture radar data

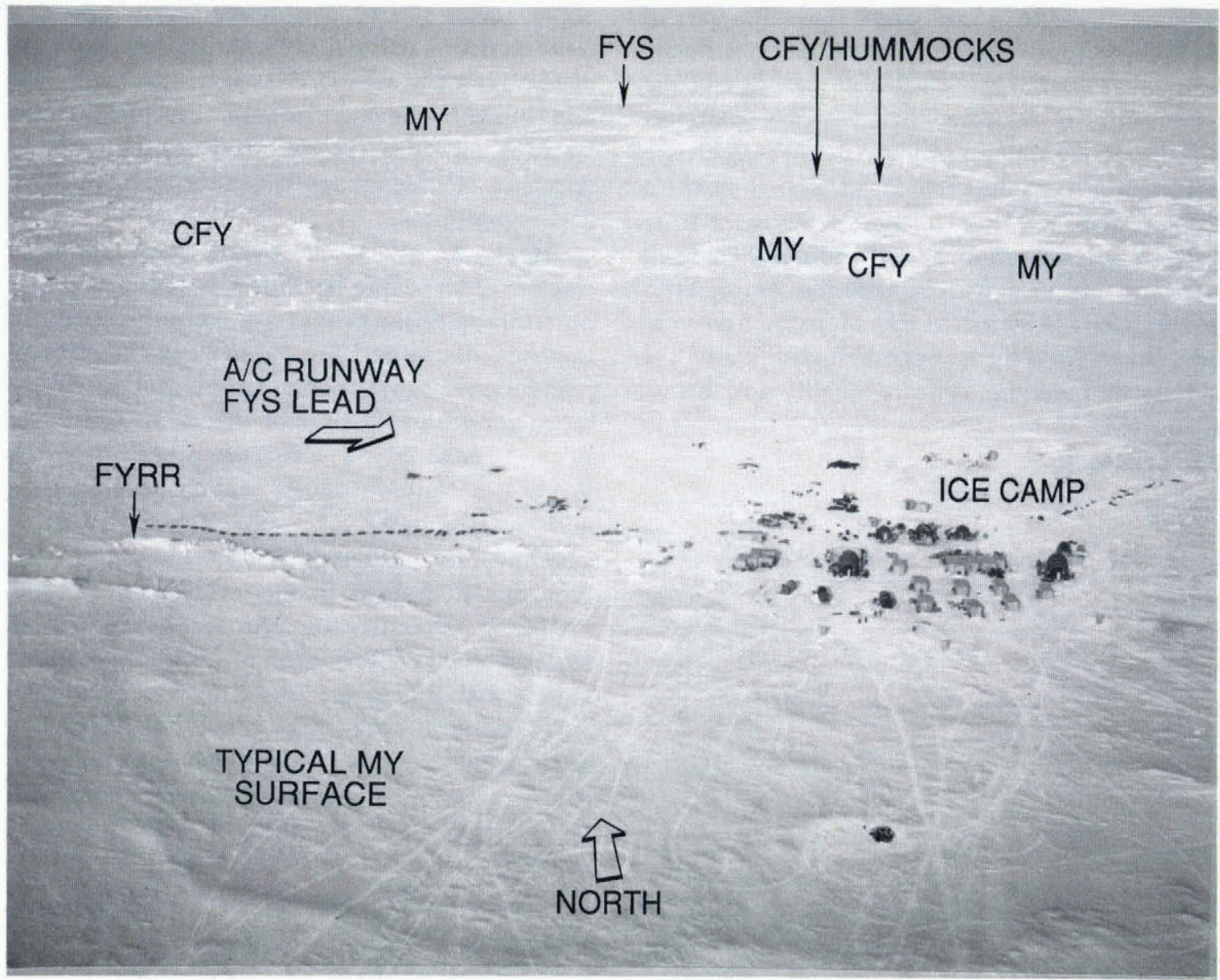

Fig. 4. Air photograph of the APLIS'88 ice camp looking north, showing areas of compressed first-year ice (CFY), multi-year ice $(M Y)$, deformed first-year ice (FYRR) and first-year smooth ice (FYS).

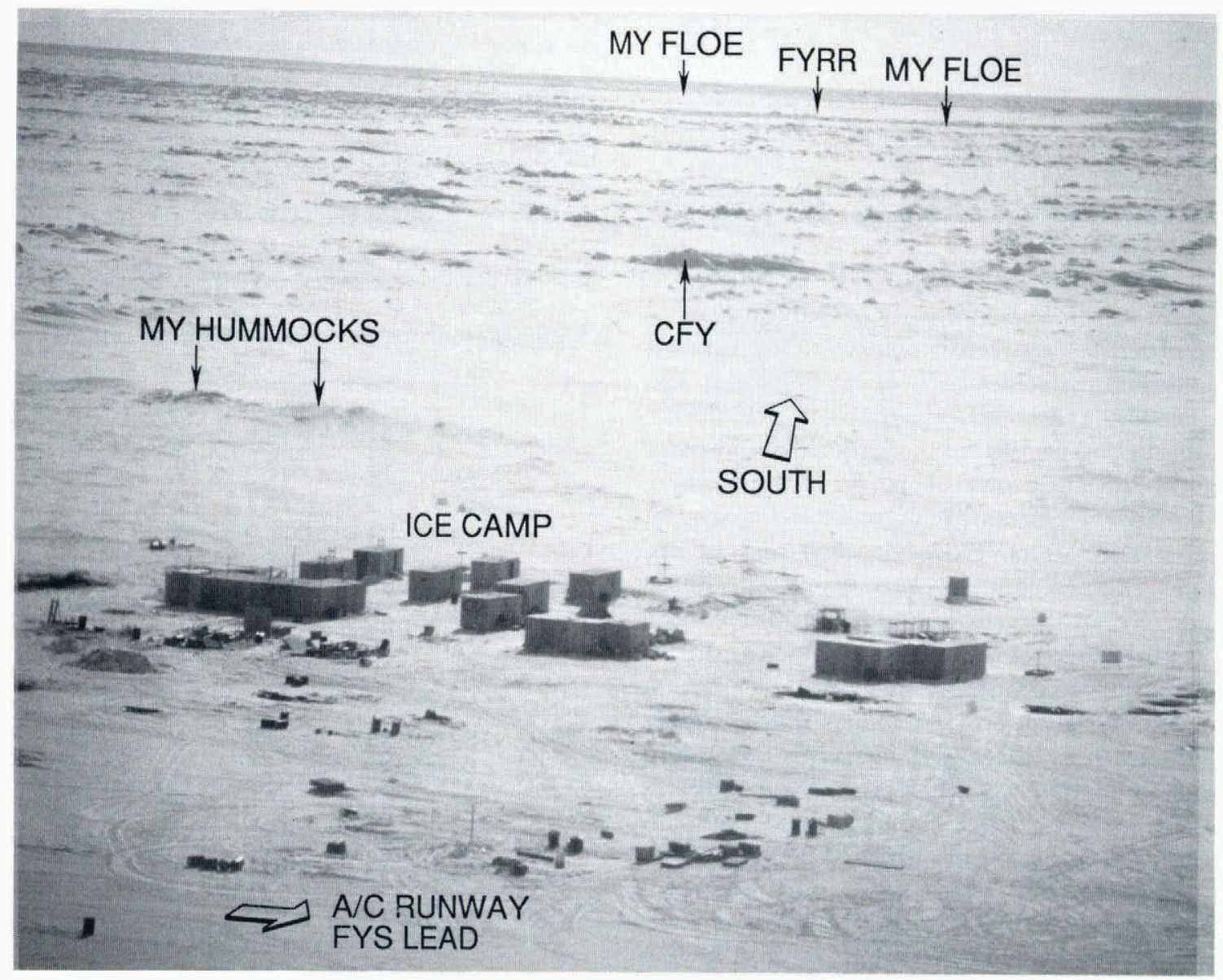

Fig. 5. Air photograph of the APLIS'B8 ice camp looking south. 
rough first-year ice and a refrozen lead. An aerial photograph looking south (Fig. 5) reveals the hummocky surface of the large multi-year ice floe at the edge of the ice camp and zones of deformed first-year ice. Examination of the underside topography by divers revealed a large spatial variability in the growth rate of first-year ice and large differences in bottom-roughness features from those of multi-year ice where rounded and polished keels with no block structure contrasted with the young keels comprising randomly oriented blocks of ice in first-year ice. Ice cores taken from the smooth first-year ice in the lead to estimate temperature, salinity, density and brinevolume profiles (Fig. 6) revealed the recently grown ice to be columnar in structure.

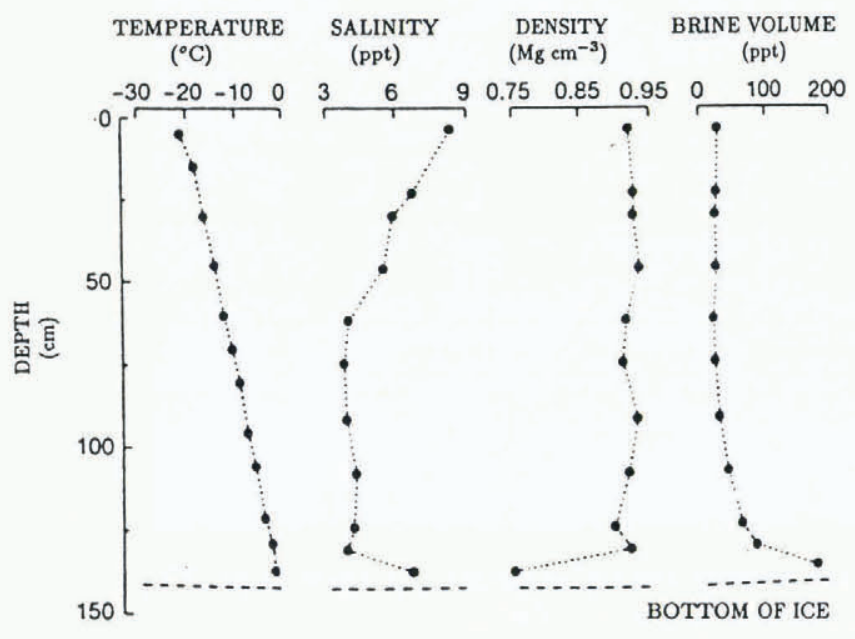

Fig. 6. Ice characteristics of an ice core taken from the $F Y$ ice lead near the ice camp APLIS'88 on 25 March 1988 (from Wen and others, 1989).

\section{SELECTION AND LABELING OF THE ICE TYPES}

Identifying ice types from remotely sensed imagery is difficult because: (1) the nomenclature of ice types is based on physical properties such as ice thickness, age, formation history, and surface roughness, which do not provide a unique relationship between ice types and radar signatures; (2) the microwave properties of sea ice vary widely with seasonal temperature (Onstott and Gogineni, 1985; Onstott and others, 1987; Cavalieri and others, 1990) and geographical location (Livingstone and others, 1987); and (3) in-situ surface observations, when available at all because of technical difficulties and costs of operation, are limited to sparse point measurements at the surface, which do not provide enough spatial details compared to the remotely sensed imagery. A standard procedure is to identify visually certain ice conditions present in the imagery, select training areas representative of each ice type, extract their microwave signatures, and then classify each image pixel into these ice conditions. This supervised procedure provides confidence in the results, and attempts at minimizing classification errors, but requires detailed independent surface information (often lacking), and homogeneous ice areas across swath, containing many pixels, and with clear and well-defined boundaries. As the dimensionality of the remotely sensed data increases (with polarimetry and multi-frequency), and the complexity of the scene features increases (in deformed first-year ice), manual selection of relevant ice classes becomes rapidly difficult and randomized.

Here, we select ice classes using an unsupervised clustering technique because it is nearly automatic; needs no training areas; provides a non-subjective characterization of unique and separable classes of radiometric and polarimetric radar back-scatter; and often performs a more sensitive selection of the mean cluster characteristics, because selection is a computer-optimized process. We use a cluster-analysis routine developed by Rignot and others (1992) for multi-parameter SAR data. To account for variations in radar back-scatter from each ice type due to changes in the incidence angle $\theta_{\mathrm{i}}$ across the swath, we separate each SAR scene into three distinctive regions, so that within each region changes in radar backscatter with $\theta_{\mathrm{i}}$ of each ice type are less than their expected separability in radar back-scatter; followed by a cluster analysis of L- and C-band polarimetric data in each region. The three regions correspond in image 1372 to: (1) $29^{\circ} \leq \theta_{\mathrm{i}} \leq 36^{\circ}$; (2) $36^{\circ} \leq \theta_{\mathrm{i}} \leq 45^{\circ}$; (3) $\theta_{\mathrm{i}} \geq 45^{\circ}$; and in image 311 to: (1) $20^{\circ} \leq \theta_{\mathrm{i}} \leq 29^{\circ}$; (2) $29^{\circ} \leq \theta_{\mathrm{i}} \leq 41^{\circ}$; (3) $\theta_{i} \geq 41^{\circ}$. The cluster-analysis routine is initialized

Table 1. Table of the polarimetric characteristics of the cluster centres of image 1372 for $\theta_{\mathrm{i}} \geq 45^{\circ}$ at $L$-, and C-band frequencies, along with their sea-ice label. $\sigma_{X Y}$ is the radar back-scatter at $X \Upsilon$-polarization expressed in $d B, \rho_{\mathrm{HHVV}^{*}}$ is the magnitude of the correlation coefficient between the $H H$ and $V V$ returns expressed in linear units, and $\phi_{\mathrm{HHVV}^{*}}$ is the mean phase difference between the $\mathrm{HH}$ and $\mathrm{VV}$ returns expressed in degrees. The noise power level at $H H$ and $V V$ polarizations, and $\theta_{\mathrm{i}}=45^{\circ}$, is $-44 d B$ at $L$-band and $-40 \mathrm{~dB}$ at $C$-band. The values of $\rho_{\mathrm{HHVV}^{*}}$ are not corrected from biases introduced by system noise

Frequency $\sigma_{\mathrm{HH}} \quad \sigma_{\mathrm{HV}} \quad \sigma_{\mathrm{VV}} \quad \phi_{\mathrm{HHVV}^{*}} \rho_{\mathrm{HHVV}^{*}}$ Ice label

$\begin{array}{lrrrrrl}\text { L- } & -33.9 & -41.6 & -27.8 & -1 & 0.57 & \text { ThI } \\ -26.5 & -38.6 & -23.6 & -10 & 0.71 & \text { FYS } \\ -21.7 & -33.4 & -19.3 & -7 & 0.74 & \text { FYR } \\ -19.2 & -33.9 & -16.2 & 0 & 0.91 & \text { MY } \\ -17.7 & -27.5 & -15.7 & -3 & 0.74 & \text { FYR } \\ -16.1 & -26.2 & -13.6 & 0 & 0.80 & \text { MY } \\ -14.1 & -24.0 & -12.3 & 0 & 0.74 & \text { FYRR } \\ -11.8 & -19.6 & -9.8 & 1 & 0.71 & \text { CFY } \\ & & & & & & \\ \text { C- } & -29.8 & -36.6 & -27.1 & 8 & 0.39 & \text { ThI } \\ -22.9 & -35.3 & -22.9 & 7 & 0.66 & \text { FYS } \\ -21.3 & -33.7 & -21.0 & 8 & 0.70 & \text { FYR } \\ -13.0 & -23.0 & -12.0 & 2 & 0.70 & \text { MY } \\ -19.5 & -31.6 & -19.1 & 10 & 0.71 & \text { FYR } \\ -12.3 & -21.3 & -11.4 & 1 & 0.63 & \text { MY } \\ -16.9 & -28.3 & -16.6 & 13 & 0.70 & \text { FYRR } \\ -12.4 & -20.9 & -11.6 & 8 & 0.58 & \text { CFY }\end{array}$


with an expected number of clusters equal to 6 for image 311 separated by at least $4 \mathrm{~dB}$, and to 7 for image 1372 (thin ice is an additional ice type present in image 1372) separated by $4 \mathrm{~dB}$. A $4 \mathrm{~dB}$ minimum separation in radar back-scatter corresponds to a theoretical classification error of the image pixels of less than 1\% (Rignot and Chellappa, 1991). The final number of clusters, which is not bound to the initial guess, is 6 for image 311 and 8 for image 1372. The radar back-scatter characteristics of the clusters are given in Tables 1 and 2 . We label the clusters into six different sea-ice types, thereby regrouping some of the clusters together into a single ice type. This

Table 2. Table of the polarimetric characteristics of the cluster centers of image 311 for $\theta_{\mathrm{i}} \geq 41^{\circ}$ at $L$-, and $C$ band frequencies, along with their sea-ice type labeling. Notations are the same as in Table 1

\section{Frequency $\sigma_{\mathrm{HH}} \quad \sigma_{\mathrm{HV}} \quad \sigma_{\mathrm{VV}} \quad \phi_{\mathrm{HHVV}^{*}} \rho_{\mathrm{HHVV}^{*}}$ Ice label}

$\begin{array}{lllllll}\text { L- } & -26.2 & -42.0 & -23.7 & 3 & 0.73 & \text { FYS } \\ -20.7 & -31.6 & -17.9 & 1 & 0.75 & \text { FYR } \\ -20.6 & -36.4 & -17.4 & 7 & 0.90 & \text { MY } \\ -17.7 & -34.1 & -15.6 & 6 & 0.90 & \text { MY } \\ -15.8 & -25.2 & -13.1 & 3 & 0.75 & \text { FYRR } \\ -12.9 & -21.3 & -10.4 & 5 & 0.71 & \text { CFY } \\ & & & & & & \\ \text { C- } & -22.2 & -31.9 & -23.7 & 1 & 0.65 & \text { FYS } \\ -19.6 & -27.2 & -20.2 & 1 & 0.64 & \text { FYR } \\ -13.8 & -20.7 & -13.8 & 2 & 0.71 & \text { MY } \\ -12.7 & -19.6 & -12.8 & 2 & 0.72 & \text { MY } \\ -14.3 & -20.4 & -14.6 & 2 & 0.67 & \text { FYRR } \\ -11.9 & -17.1 & -12.3 & 2 & 0.61 & \text { CFY }\end{array}$

regrouping of clusters is expected to be part of the selection process as clustering provides image classes independent from the fact that they may or may not share similar geophysical characteristics. Several clusters are expected in first-year ice because of the large dynamic range in radar back-scatter of first-year ice due to spatial changes in small-scale surface roughness, and the presence of pressure ridges and rubble fields. Multiple clusters are also expected in multi-year ice due to the variety of constituents that contribute to its radar signatures, including multi-year smooth/flat ice, hummocks, pressure ridges and melt-pools (Onstott, 1992). Independently in each region, each image pixel is subsequently classified into one of these ice classes using a Maximum A Posteriori (MAP) Bayesian classifier for multi-parameter SAR data (Rignot and Chellappa, 1992). The resulting sub-images are reconstituted, and matching is found to be excellent at the boundaries. P-band is not used because it is similar to L-band and reduces the classification quality for thin ice of low back-scatter. The six identified ice conditions are labeled in the following fashion (Figs 1c and 2c): (1) old compressed first-year ice (CFY); (2) firstyear rubble and ridges (FYRR); (3) multi-year ice (MY);
(4) first-year rough and deformed ice (FYR); (5) firstyear smooth and undeformed ice (FYS); and (6) thin first-year ice (ThI).

Figure 7 shows examples of radar back-scatter curves for the six ice types present in image 1372. The plotted values are obtained for each ice type by averaging along each range line (same incidence angle) the radar backscatter values of all the pixels classified into that particular ice type in Figure 1c, and smoothing the results using a ten-point moving window. The curves illustrate the separability between the different ice types at $\mathrm{HH}$ - and $\mathrm{HV}$-polarization versus $\theta_{\mathrm{i}}$. At C-band, MY and CFY are confused, except from a small contrast at HV-polarization, but MY and FY are separated by several $\mathrm{dB}$. The continuity of the curves at the transition between different regions confirms that matching of the sub-images is satisfactory. The radar back-scatter curves at L-band are consistent with published scatterometer measurements (Fig. 2; Onstott and others, 1982), including the more rapid decay of $\mathrm{MY}$ with $\theta_{\mathrm{i}}$ at $\mathrm{HH}$ polarization compared to FY (Fig. 5; Onstott and others, 1979). Radar back-scatter values at HV-polarization are less sensitive to $\theta_{\mathrm{i}}$ because volume-scattering effects dominate the radar returns and are less dependent upon incidence angle.

Figure 1d shows the brightness temperatures of the ice obtained from air-borne passive microwave data acquired by NORDA's $\mathrm{K}_{\mathrm{a}}$-band $(33.6 \mathrm{GHz})$, V-polarization, Radiometric Mapping System (KRMS) (Eppler and others, 1986) at the same location as image 1372. KRMS data were not available for image 311 . The KRMS data were calibrated using the procedure described in Farmer and others (1990), and were resampled and projected into slant-range to facilitate intercomparison with the slantrange SAR data. The spatial resolution of the KRMS data is $145 \mathrm{~m}$ in the center of the swath, decreasing towards the edges of the swath with increasing geometric distortions. Because of residual calibration errors, geometric distortions, and coarse spatial resolution, the KRMS imagery is only used here to indicate the presence of certain ice types, and not as a validation procedure of the SAR results per se. Nevertheless, the brightness temperatures $T_{\mathrm{B}}$ together with the contextual information clearly indicate the presence of multi-year ice (MY), first-year ice (FY), and thin ice (ThI); although MY is not well separated from ThI by $T_{\mathrm{B}}$ alone (Table 3 ). MY is colder than FY. ThI is the coldest, but not cold enough to correspond to open water since $T_{\mathrm{B}}=141 \mathrm{~K} \pm$ $1 \mathrm{~K}$ for calm and cool open water (personal communication from D. T. Eppler, 1992).

ThI is distinguished in image 1372 by its low radar back-scatter at all frequencies, and by the obvious presence of a recently frozen lead in the center of the scene consistent with the ice drift and divergence recorded in the nearby ice camp on $10 \mathrm{March}$. The polarimetric characteristics of ThI at L-band provide evidence that it does not contain any open water. The small perturbation model (SPM) (Rice, 1951) predicts that for slightly rough surfaces the ratio $\gamma=\sigma_{\mathrm{Vv}} / \sigma_{\mathrm{HH}}$ increases with the incidence angle $\theta_{\mathrm{i}}$ and the real part of the dielectric constant $\epsilon_{\mathrm{r}}$ of the surface, independent of the rms height of the surface at the wavelength scale. Since $\epsilon_{\mathrm{r}}$ increases with ice salinity, $\gamma$ is expected to be larger in young thin 

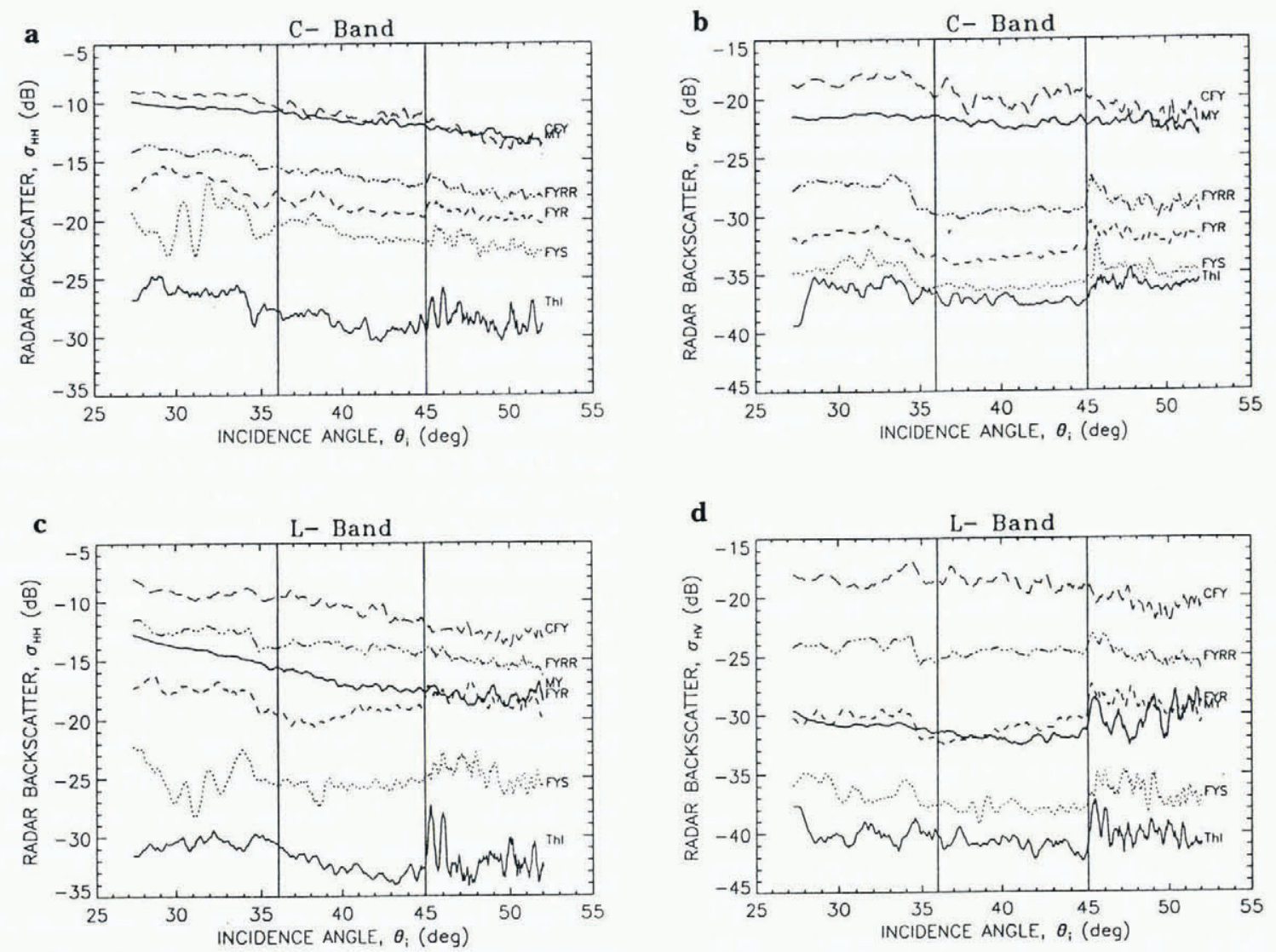

Fig. 7. Radar back-scatter curves $\sigma$ of six types identified in image 1372 vs the incidence angle $\theta_{\mathrm{i}}$ at (a) C-band $\mathrm{HH}$ polarization; (b) C-band HV-polarization; (c) L-band HH-polarization; (d) L-band HV-polarization. Vertical lines indicate the limits of the three regions used for clustering of the multi-parameter SAR data.

FY ice than in thick FY ice, which in turn should have a larger $\gamma$ than in MY ice; and $\gamma$ is largest in open water. Assuming SPM applicable to smooth sea ice at L-band (Winebrenner and others, 1989), we inverted $\gamma$ of the pixels classified as ThI in image 1372 (Fig. 1c) for $\epsilon_{\mathrm{r}}$. The histogram of $\epsilon_{\mathrm{r}}$ values is shown in Figure 8. System noisepower level estimates were used to correct $\gamma$ from the bias introduced by system noise in thin ice of low back-scatter. $\epsilon_{\mathrm{r}}$ of ThI is large in average, yet much lower than that expected for open water $\left(\epsilon_{\mathrm{r}}=80\right)$ for which SPM is applicable when the wind speed is low and the r.m.s. height of the water surface is typically less than one-tenth of the wavelength (Kim and others, 1992). If open water were present in the ThI lead, its surface would have to be

Table 3. Table of brightness temperature $T_{\mathrm{B}}$ (in $K$ ) and standard deviations $\sigma_{T_{\mathrm{B}}}$ of five ice types in image 1372
Ice type
$T_{\mathrm{B}} \pm \sigma_{T_{\mathrm{B}}}$

$\begin{array}{ll}\text { ThI } & 150 \pm 13 \\ \text { FYS } & 208 \pm 3 \\ \text { FYR } & 217 \pm 2 \\ \text { MY } & 156 \pm 3 \\ \text { CFY } & 182 \pm 5\end{array}$

very smooth because the radar back-scatter values recorded in the lead are very low. Assuming an ice temperature of $-5^{\circ} \mathrm{C}$ (i.e. that no snow cover was present on ThI, and that the air temperature was $-10^{\circ} \mathrm{C}$ ), an ice density of $0.90 \mathrm{Mg} \mathrm{m}^{-3}$ in columnar sea ice, and using the dielectric mixing formulae of Vant and others (1974, 1978) and the modified phase relations for brine in sea ice of Stogryn and Desargent (1985), we find that in order to obtain $\epsilon_{\mathrm{r}}$ values exceeding 6.0 , it is necessary to have a salinity greater than $43 \mathrm{ppt}$, corresponding to a brine volume greater than $0.423 \mathrm{ppt}$. The only possibility for observing the dielectric constant values shown in Figure 8 is therefore for the ThI lead to include large quantities of brine in slush or liquid form at the surface. Drinkwater and Crocker (1988) reported salinities of such surfaces as exceeding $100 \mathrm{ppt}$. The large spread of $\epsilon_{\mathrm{r}}$ values suggests large inhomogeneities within the lead ice. These results from radar back-scatter model inversion are consistent with a recent lead formation a day or so prior to flight, followed by a rapid freeze-up due to the cold air temperatures (Fig. 3). Ice thicknesses were likely in the few $\mathrm{cm}$ range. We did not perform a similar inversion at C-band because $\gamma$ offers less contrast between ThI ice and open water, roughness effects become significant at this shorter wavelength, and SPM no longer applies (Kim and others, 1992). More complicated inversion models must be developed to account for the effect of both dielectric constant and surface roughness on the radar returns at the shorter wavelengths. Several candidate algorithms incorporating both effects are currently under active testing in related research projects (e.g. Oh and others, 1992). 


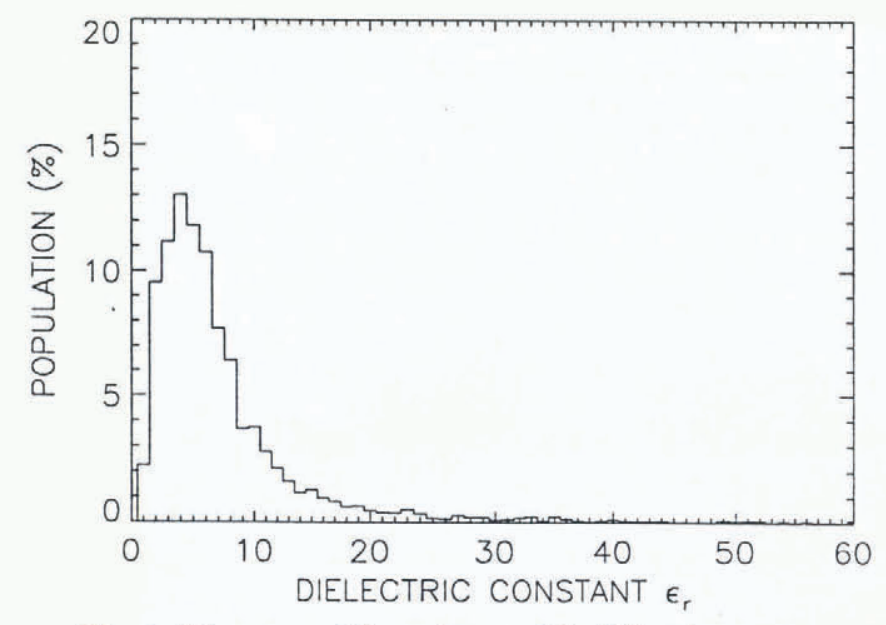

Fig. 8. Histogram of the real part of the dielectric constant of thin ice in image 1372 at L-band frequency using the small perturbation model. The median value of the distribution is $\epsilon_{\mathrm{r}}=6$ and the standard deviation is 4.5 .

Labeling MY ice is facilitated by the highly recognizable rounded shape of MY floes, their cold brightness temperatures in the KRMS data in image 1372, and their existence at the ice camp. The boundaries of MY ice floes appear distinctly in the aerial photographs (Figs 4 and 5) due to a sharp transition in surface roughness, and in the L-band $\mathrm{HH}$ imagery (Figs $1 \mathrm{~b}$ and $2 \mathrm{~b}$ ) due to a sharp transition in radar brightness. MY in image 1372 has radar back-scatter characteristics that are similar to those measured in image 311 (Tables 1 and 2). An exception is the large fragmented MY ice floe in the center of image 311 which includes numerous patches of CFY which correspond to the hummocks and ridges reported in Wen and others (1989), and the features visible in Figure 5.

FYRR comprises extensive pressure ridges and rubbled fields of broken blocks of upstanding ice in the highly deformed FY ice present in the two scenes (Figs 4 and 5). Ridges are geophysically important because they modulate the drag coefficient of the surface strongly (Burns, 1990), and account for a significant portion of the total ice mass. FYR also comprises rough, deformed FY ice, but does not include pressure ridges, and is less deformed and less rough than FYRR. Radar back-scatter model predictions clearly indicate that differences in radar back-scatter from deformed FY ice are mostly due to differences in small-scale surface roughness as opposed to differences in dielectric constant and ridge structure (Manninen, 1991). Breaking rough first-year ice into two distinct classes is also relevant in our context since MY has an intermediate range of radar back-scatter between FYR and FYRR at L-band (Fig. 7c), whereas MY is consistently brighter than both ice types at C-band (Fig. 7a and b), which explains why FYRR is likely to be misclassified as MY ice at L-band and not at C-band. FYS is another FY ice type that is easily identified due to its existence at the location of the aircraft runway in image 311, and its low radar back-scatter in images 1372 and 311 , indicating a smoother surface at the wavelength scale.

CFY is deformed, rough ice which is mixed with MY ice at C-band and with deformed FY at L-band. No salinity profile was acquired at that particular location to establish on a strong basis that CFY is indeed FY ice; but examination of aerial photographs, KRMS data, and polarimetric SAR characteristics concur to indicate that CFY is younger than the MY ice which it glues together. The brightness temperature of CFY is $16 \mathrm{~K}$ warmer than that of MY ice although not as warm as the other types of FY ice, indicating an ice type younger than MY ice. CFY ice coincides with highly deformed surfaces consisting of large uplifted ice blocks both within and surrounding MY ice floes (Figs 4 and 5), clearly generated by compression and shear forces during ice drifting, indicating that CFY is very deformed FY ice that surrounds the MY floes. In both Tables 1 and 2, at L-band, the correlation coefficient between $\mathrm{HH}$ and $\mathrm{VV}$, denoted $\rho_{\mathrm{HHVV}}$, is 0.9 for MY ice, and only 0.7 for FY and CFY ice. A higher correlation between $\mathrm{HH}$ and VV is expected in MY which exhibits azimuthal symmetry and for which scatterers are isotropically distributed (Nghiem and others, 1992). In contrast, first-year ice has preferential vertical structures observed in the orientation of brine inclusions (Weeks and Ackley, 1982), yielding lower values of $\rho_{\mathrm{HHVV}}{ }^{*}$ because $\mathrm{HH}$ and VV signals are not sensitive to the same saline inclusions and thereby the same distribution of scatterers. A lower value of $\rho_{\mathrm{HHVV}^{*}}$ in CFY indicates more pronounced heterogeneities in salinity in CFY than in MY ice, and hence a younger ice type. The higher radar back-scatter of CFY at L- and C-band compared to other FY ice types is consistent with a much rougher surface, comprised of blocks of FY ice from ice pushed up and uplifted around the edges of the larger, thicker, and more massive MY ice floes. CFY is not distinguished from MY at C-band, except for a 1-2 dB contrast at HVpolarization. Multiple surface scatter from this lower salinity CFY (because of uplift and drainage), together with penetration and volume scatter from voids between blocks, could explain microwave signatures equivalent to that of smooth MY at C-band.

Estimating the classification error of the ice maps in Figures $1 c$ and $2 c$ is difficult in the absence of surface observations on a pixel-by-pixel basis, as typical of most remote-sensing experiments. Errors due to the classifier itself are of second-order magnitude due to the large contrast between ice types. Classification performance is therefore only limited by system errors (interferences, processing artifacts), and by confusion of certain ice types by the radar. In Figure 1c, FY is misclassified as MY in one line running in the center from top to bottom because of the corrupting influence of system interference in the Cband H-received channel. These errors do not appear in Figure 9c since C-band H-received channel is not used. In both Figures 1c and 2c, small patches of FY ice are detected within MY ice floes that could correspond to melt ponds. Refrozen melt ponds are perhaps misclassified as FY ice by the radar because the surface is likely very smooth and bubble-free. Similarly, a number of MY floes include segments of CFY ice which may correspond to MY pressure ridges or hummocks and are therefore misclassified as FY ice. MY pressure ridges are typically composed of blocks of ice with tilted surfaces that produce strong back-scatter due to scattering from individual facets, multiple facet scattering, and in some cases enhanced volume scattering due to a transition to a very low density ice form (Onstott, 1992), so that they may 


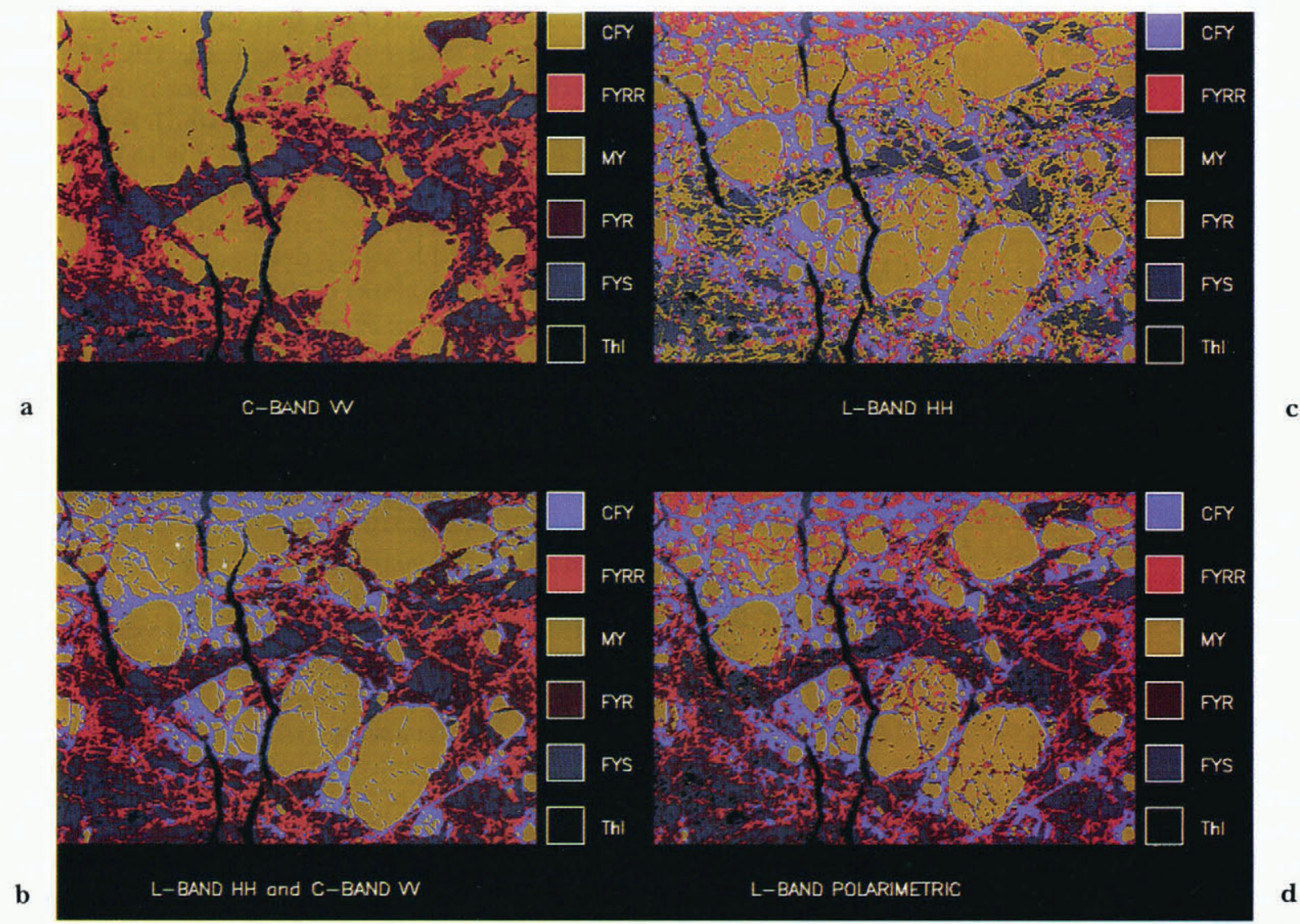

Fig. 9. Classification map of image 1372 into six sea ice types at (a) C-band VV-polarization; (b) L-band HHpolarization; (c) C-band VV-polarization and L-band HH-polarization combined; (d) L-band polarimetric.

share common scattering characteristics with CFY ice. Except for the case of the large MY floe in the center of Figure 2c which is obviously fragmented and held together by large patches of CFY, CFY ice in the midst of MY ice floes should really be classified as MY ice, while CFY ice surrounding the MY ice floes and holding them together is not MY ice. By counting all the visually identified misclassified pixels discussed above, we estimated the classification accuracy of the ice maps in Figures $1 \mathrm{c}$ and $2 \mathrm{c}$ to be greater than $90 \%$.

Gray and others (1982) reported similar classification accuracies combining scatterometer and radiometer data acquired over the Beaufort Sea in March-April 1979 to six separate ice conditions. In this study, we only use the radar data to identify the six ice conditions. Our classification software is more sophisticated, and classification accuracies are computed for all image pixels instead of being limited to homogeneous training sites. Combining frequencies and polarizations is essential for ice-type labeling. At a single-polarization, L-band reveals ridges and MY ice-floe boundaries, while C-band provides a large contrast in radar back-scatter between MY and FY ice. In FY ice, differences in radar backscatter are interpreted as differences in small-scale surface roughness to identify different categories of deformed FY ice. At L-band, with two polarizations, $\gamma$ helps separate thin ice from thicker FY ice and thin ice from calm open water, and $\rho_{\mathrm{HHVV}^{*}}$ is a key parameter for labeling CFY ice as FY ice instead of MY ice.

\section{CLASSIFICATION ACCURACY VS FREQUENCY AND POLARIZATION}

The ice map obtained using L- and C-band polarimetric combined (Fig. 1c) is used as a reference map of the ice types present in image 1372, and ideally for the present time its classification accuracy is assumed to be $100 \%$. Reclassified images are then generated using a reduced number of polarizations and frequencies, and a relative classification accuracy of each type is computed in reference to the classification map in Figure 1c and then recorded in confusion matrices. A representative sample of the confusion matrices obtained for each test case is given in Table 4 for image 1372 with $\theta_{\mathrm{i}} \geq 45^{\circ}$. Each confusion matrix indicates how classification inaccuracy results in rebinning of pixels in the wrong ice classes, along with the percentage of misclassified pixels. Vertical columns indicate how, for a particular ice class, various pixels are misclassified. Each vertical column totals $100 \%$, and components of each vertical column denote the percentage of misclassification (as other classes) relative to the results in Figure 1c. An overall relative classification accuracy of each combination of channels is computed from the average of the diagonal elements in each of the confusion matrices. These confusion matrices are computed from all the pixels included in the image. To simplify the presentation, FYRR and FYR are regrouped into one ice class, denoted FYR, as both correspond to deformed FY ice but with a larger variance. 
Table 4. Confusion matrices of five ice types at (a) C-band VV; (b) C-band $H V$; (c) C-band $H H$ and $H V$; (d) $C$ band $\mathrm{HH}$ and $\mathrm{VV}$; (e) C-band full polarimetry; (f) L-band $H H ;(g) L$-band $H H$ and $V V$; (h) L-band full polarimetry; (i) P-band HH and VV; (j) P-band full polarimetry; (k) L-band HH and C-band VV; (l) L-band $H V$ and $\mathrm{C}$-band $\mathrm{HH}$

Ice type ThI FYS FYR MY GFY

Ice type ThI FYS FYR MY CFY

\begin{tabular}{llrrrrrrrrrrr}
\hline & ThI & 97 & 17 & 1 & 0 & 0 & ThI & 83 & 26 & 2 & 0 & 0 \\
& FYS & 3 & 54 & 15 & 0 & 0 & FYS & 14 & 49 & 11 & 0 & 0 \\
(a) FYR & 0 & 29 & 83 & 1 & 16 & (b) & FYR & 3 & 25 & 86 & 1 & 11 \\
MY & 0 & 0 & 1 & 51 & 35 & MY & 0 & 0 & 1 & 84 & 44 \\
CFY & 0 & 0 & 0 & 48 & 49 & CFY & 0 & 0 & 0 & 15 & 45 \\
\hline
\end{tabular}

Ice type ThI FYS FYR MY CFY

Ice type ThI FYS FYR MY CFY

\begin{tabular}{|c|c|c|c|c|c|c|c|c|c|c|c|c|c|}
\hline \multirow{5}{*}{ (c) } & ThI & 96 & 4 & 0 & 0 & 0 & \multirow{5}{*}{ (d) } & ThI & 98 & 5 & 0 & 0 & 0 \\
\hline & FYS & 4 & 76 & 13 & 0 & 0 & & FYS & 2 & 70 & 15 & 0 & 0 \\
\hline & FYR & 0 & 20 & 86 & 1 & 10 & & FYR & 0 & 25 & 84 & 1 & 12 \\
\hline & MY & 0 & 0 & 1 & 81 & 45 & & MY & 0 & 0 & 1 & 77 & 40 \\
\hline & CFY & 0 & 0 & 0 & 18 & 45 & & CFY & 0 & 0 & 0 & 22 & 48 \\
\hline
\end{tabular}

Ice type ThI FYS FYR MY CFY

Ice type ThI FYS FYR MY CFY

\begin{tabular}{|c|c|c|c|c|c|c|c|c|c|c|c|c|c|}
\hline & ThI & 98 & 6 & 0 & 0 & 0 & \multirow{5}{*}{ (f) } & ThI & 98 & 13 & 0 & 0 & 0 \\
\hline \multirow{4}{*}{ (e) } & FYS & 2 & 74 & 12 & 0 & 0 & & FYS & 2 & 83 & 8 & 1 & 0 \\
\hline & FYR & 0 & 20 & 87 & 1 & 9 & & FYR & 0 & 3 & 65 & 31 & 31 \\
\hline & MY & 0 & 0 & 1 & 81 & 44 & & MY & 0 & 1 & 21 & 68 & 4 \\
\hline & CFY & 0 & 0 & 0 & 18 & 47 & & CFY & 0 & 0 & 6 & 0 & 64 \\
\hline
\end{tabular}

Ice type ThI FYS FYR MY CFY

Ice type ThI FYS FYR $\quad$ MY $\quad$ CFY

\begin{tabular}{rrrrrrrrrrrrrr}
\hline & ThI & 96 & 12 & 0 & 0 & 0 & & ThI & 95 & 13 & 0 & 0 & 0 \\
& FYS & 4 & 86 & 6 & 0 & 0 & FYS & 5 & 84 & 5 & 1 & 0 \\
(g) & FYR & 0 & 1 & 87 & 7 & 34 & (h) & FYR & 0 & 1 & 87 & 11 & 32 \\
MY & 0 & 1 & 3 & 93 & 1 & MY & 0 & 2 & 5 & 88 & 0 \\
CFY & 0 & 0 & 4 & 0 & 65 & CFY & 0 & 0 & 3 & 0 & 68 \\
\end{tabular}

Ice type ThI FYS FYR MY CFY

Ice type ThI FYS FYR MY CFY

\begin{tabular}{|c|c|c|c|c|c|c|c|c|c|c|c|c|c|}
\hline \multirow{6}{*}{ (i) } & ThI & 95 & 42 & 1 & 0 & 0 & \multirow{5}{*}{ (j) } & ThI & 69 & 27 & 4 & 0 & 1 \\
\hline & FYS & 5 & 47 & 17 & 6 & 0 & & FYS & 11 & 35 & 14 & 2 & 1 \\
\hline & FYR & 0 & 8 & 59 & 5 & 30 & & FYR & 17 & 33 & 66 & 13 & 40 \\
\hline & MY & 0 & 3 & 3 & 89 & 10 & & MY & 1 & 3 & 2 & 82 & 17 \\
\hline & CFY & 0 & 0 & 20 & 0 & 60 & & CFY & 2 & 2 & 14 & 3 & 41 \\
\hline & Ice type & ThI & FYS & FYR & MY & CFY & & Ice type & ThI & FYS & FYR & MY & CFY \\
\hline \multirow{5}{*}{ (k) } & ThI & 99 & 11 & 0 & 0 & 0 & \multirow{5}{*}{ (l) } & ThI & 98 & 5 & 0 & 0 & 0 \\
\hline & FYS & 1 & 84 & 7 & 0 & 0 & & FYS & 2 & 86 & 8 & 0 & 0 \\
\hline & FYR & 0 & 5 & 91 & 1 & 12 & & FYR & 0 & 9 & 90 & 1 & 13 \\
\hline & MY & 0 & 0 & 1 & 98 & 10 & & MY & 0 & 0 & 1 & 98 & 2 \\
\hline & CYF & 0 & 0 & 1 & 1 & 78 & & CFY & 0 & 0 & 1 & 1 & 85 \\
\hline
\end{tabular}


At C-band, a large contrast in radar back-scatter exists between MY and undeformed FY (Fig. 7) due to the additional volume back-scatter of the low-density bubble-rich layer contained in the upper part of the MY sea ice (Kim and others, 1984). Yet C-band VVpolarization alone achieves only $67 \%$ overall relative classification accuracy (Table 4a) because MY and CFY are not separated. C-band HV-polarization better separates MY and CFY, and MY and FY, but confuses ThI and FYS, yielding a $69 \%$ classification accuracy (Table 4b). C-band HH-polarization has a relative classification accuracy of $71 \%$. C-band HH- and HVpolarizations combined increase the C-band VV-polarization results by $10 \%$ (Table $4 \mathrm{c}$ ). Other combinations of two polarimetric channels yield similar relative accuracies (Table 4d). The best results are obtained using the complete polarimetry (Table 4e), but two polarizations perform nearly as well and significantly better than one polarization.

The contrast between MY and FY is reduced at Lband (Fig. 7) because MY generates almost no additional volume scattering (Winebrenner and others, 1989). Classification accuracy is $75 \%$ at L-band $\mathrm{HH}$-polarization because MY is confused with FYRR and CFY (Table 4f), confirming that L-band at one polarization is not useful for ice mapping (Onstott and others, 1982; Lyden and others, 1984). Two like-polarization channels however improve the relative accuracy by $9 \%$ (Table $4 \mathrm{~g}$ ). The full polarimetry does not improve the results and actually yields a $1 \%$ drop in accuracy because the HV radar returns increase confusion between MY and FYR (Table 4h; Fig. 7d). This result shows that increasing the number of channels does not necessarily increase classification accuracy in a polarimetric classifier. Notwithstanding this observation, L-band performs better than C-band over all classes when more than one polarization is used, despite the reduced contrast between MY and deformed FY ice.

P-band is similar to L-band with a reduced contrast between MY and FY. P-band is not considered as particularly useful for ice mapping (Parashar and others, 1977), but the classification results are reported here for sake of completeness. The classification accuracy is $60 \%$ at $\mathrm{HH}$-polarization, $70 \%$ at $\mathrm{HH}$ - and VVpolarizations combined (Table $4 \mathrm{i}$ ), and only $58 \%$ with the full polarimetry (Table $4 \mathrm{j})$. The HV returns confuse several ice types resulting in a relative accuracy of $48 \%$ when used alone, and in a poor performance of the full polarimetry.

Finally, the classification accuracy combining two frequencies at one polarization is investigated. L-band $\mathrm{HH}$-polarization and C-band VV-polarization have an overall relative accuracy of $90 \%$ (Table $4 \mathrm{k}$ ), which is better than any fully polarimetric single frequency or indeed any non-polarimetric single frequency. Other combinations using $\mathrm{L}$-band and $\mathrm{C}$-band at a single polarization yield similar results (Table 4l). A summary comparison of the performance of various combinations of frequencies and polarizations is shown in Figure 9 with complete ice maps of image 1372 over the entire range of incidence angle at C-band VV, L-band $\mathrm{HH}, \mathrm{L}$-band $\mathrm{HH}$ and C-band VV combined, and L-band polarimetric. MY and CFY have the same color at C-band VV (Fig. 9a) because they are not separated. Floe boundaries are not distinguishable, and the MY ice fraction is clearly overestimated. This classification result, which uses the same image as in Kwok and others (1992), illustrates the inaccuracies inherent to a C-band ice-classification scene in a transition zone where CFY is present in large quantities. At L-band HH (Fig. 9b), MY floe boundaries appear clearly, but many ice pixels in deformed FY ice are misclassified as MY ice. Combining the two frequencies yields a large improvement in classification accuracy, and the ice map (Fig. 9c) even compares favorably to the one in Figure 1c, since errors induced by system interference are eliminated. This result shows that ice mapping could improve significantly by combining ERS-1 and J-ERS-1 SAR data, provided that both sensors could image the same area at the same time. MY ice-floe boundaries appear distinctly, MY is separated from CFY, and the distribution of ridges can be extracted. The results obtained using L-band polarimetry (Fig. 9d) confirm that polarimetry is more useful at L-band than at C-band for ice mapping (Table $4 \mathrm{e}$ and $\mathrm{h}$ ), and Table $4 \mathrm{~g}$ shows that only two channels are needed at L-band to yield classification accuracies only $7 \%$ lower than that obtained using L- and C-band polarimetric.

\section{COMPARISON OF ICE-FRACTION ESTIMATES}

Ice maps generated from SAR data yield estimates of the old ice fraction used for multisensor comparisons and for evaluation of the quantity of sea ice that survives summer

Table 5. Table of ice fractions (\%) at various polarizations and frequencies. Columns without any polarization denoted indicate that the complete polarimetry is used. An asterisk indicates that errors are present, due to the contribution of a significant number of misclassified pixels to the totals shown

$\begin{array}{lllllllll}\text { Ice fraction } & C_{\mathrm{HH}} & C_{\mathrm{VV}} & C & L_{\mathrm{HH}} & L_{\mathrm{VV}} & L & L_{\mathrm{HH}}, C_{\mathrm{VV}} & L_{\mathrm{HH}}, C_{\mathrm{HH}}\end{array} \quad L, C$

\begin{tabular}{lcccccrrrr}
\hline & & & & & & & & 27 & 25 \\
Old (MY) & $40^{*}$ & $40^{*}$ & $40^{*}$ & $40^{*}$ & $40^{*}$ & 25 & 27 & 41 & 42 \\
Thick (MY, CFY) & 40 & 40 & 40 & 40 & 43 & 38 & 41 & 4 & 3 \\
Thin (ThI) & 3 & 5 & 3 & 4 & 5 & 4 & 4 &
\end{tabular}


melt, the thick-ice fraction used for fresh-water budget calculations, and the thin-ice fraction for area heat-flux estimates. Table 5 shows estimates of the old-, thick- and thin-ice fractions computed using various frequencies and polarizations for image 1372 . CFY is regrouped with MY for estimation of the thick-ice fraction because CFY probably corresponds to extremely thick FY, possibly as thick as MY because of compression, ridging, and uplifting (Johansson and Askne, 1987). At C-band VV, the old ice fraction for the entire scene is overestimated by $15 \%$. For $\theta_{\mathrm{i}} \leq 30^{\circ}$, which corresponds to the imaging conditions of ERS-1 (Attema, 1991), the error is $18 \%$ in Figure $9 \mathrm{a}$. The erropr is $20 \%$ for image 311 (C-band VV ice map not shown in the paper). Hence, ERS-1 probably overestimates the old-ice fraction in transition zones where CFY is present in large quantities. On the other hand, the error in the thick-ice fraction is less than $3 \%$ in Figure 9a, independent of $\theta_{i}$, suggesting that ERS-1 SAR provides reliable estimates of the thick-ice fraction. The results obtained at $\mathrm{C}$-band $\mathrm{HH}$ are similar, indicating that Radarsat, despite different imaging conditions (Raney and others, 1991), would also overestimate the old-ice fraction by $15 \%$, and provide reliable estimates of the thick-ice fraction. At a single polarization, L-band largely misestimates both the old- and thick-ice fractions because MY and FY ice are not well-separated, indicating that J-ERS-1 would perform poorly in similar conditions. The addition of a second polarization at Lband however yields good estimates of both the old- $(0 \%$ error compared to the last column of Table 5, and little confusion in Table $4 \mathrm{~g}$ ) and thick-ice fractions (4\% error in Table 5, and little confusion in Table $4 \mathrm{~h}$ ). The results obtained combining L- and C-band at a single polarization are even better ( $2 \%$ error in Table 5 , and little confusion in Table $4 \mathrm{k}$ ). Combining ERS-1 or Radarsat with J-ERS-1 could therefore improve the accuracy of ice-fraction estimates significantly compared to that obtained using each sensor separately, and also provide information on the spatial distribution of ridges which has been related to the spatial variability in atmospheric drag coefficient of the surface (Burns, 1990).

MY/old-ice fraction estimates are extensively used for multi-sensor comparisons and for validation of passive microwave sea-ice algorithms (Cavalieri, 1992). Compared to space-borne, passive, microwave systems, SARs benefit from a much higher spatial resolution which permits them to separate MY and FY ice better, and distinguish several additional sub-categories of MY and FY ice. Nevertheless, single-frequency, single-polarization, space-borne SARs also have their limitations for sea-ice mapping. Our results shows that ERS-1 and Radarsat would systematically overestimate the MY ice fraction in transition zones where CFY is present in large quantities. The error could be drastically reduced if ERS1 or Radarsat data were combined with J-ERS-1 data. Both sensors need to cover the same area almost simultaneously, since ice motion and changing environmental conditions set limits on the registration and synergistic use of multi-sensor datasets.

The thin-ice fraction is correctly estimated at both Land C-band in image 1372. C-band VV-polarization overestimates the thin-ice fraction by $2 \%$ compared to Cband $\mathrm{HH}$-polarization because the contrast between FYS and ThI is $2 \mathrm{~dB}$ smaller at C-band VV (VV-signals increase faster with increasing $\epsilon_{\mathrm{r}}$ than $\mathrm{HH}$-signals), hence reducing the classification accuracy of thin ice of low back-scatter (Tables 1 and 2). For the same reason, Lband VV-polarization overestimates the thin-ice fraction compared to L-band $\mathrm{HH}$-polarization.

There is currently no algorithm for separating thin ice from open water using single-channel SAR data. In this study, we showed that using two polarizations at one frequency, preferably one for which the r.m.s. height of the surface is much smaller than the radar wavelength, one could separate thin ice from open water in calm conditions based on differences in dielectric properties. Perhaps additional sub-categories of thin-ice type can be separated using the same approach. Considerations for noise-limited signals of space-borne systems are however of considerable importance since the radar back-scatter from thin ice and open water is likely to be close to the system noise power level floor, hence setting limits on their separability. In the scenes analyzed in this paper, and other scenes acquired in the Beaufort Sea during the same period, the thin-ice fraction is too small to obtain conclusive results. In the SAR scenes collected over the Bering and Chukchi Seas in March 1988, FY ice is present in larger quantities and different types of thin ice are clearly distinguished (Drinkwater and others, 1991), but we have no correlative information to validate the labeling of image classes into ice conditions and estimate classification accuracy. Further studies are required to evaluate more completely the potential of polarimetric SARs for thinner ice-type discrimination.

\section{CONGLUSIONS}

This paper presents examples of quantitative improvements in classification accuracy of six winter ice conditions using SAR data at various frequencies and polarizations combined. The indications are that $10 \%$ improvement in classification accuracy results from the use of two polarizations instead of a single polarization. Single-frequency full polarimetry does not significantly add to classification accuracy. Simply combining C- and L-band frequency at a single polarization improves classification accuracy by $10-20 \%$. The addition of Pband does not improve the results. C- and L-band frequency at two polarizations would perform nearly as well as L-, C- and P-bands fully polarimetric combined, in terms of separating the ice conditions discussed in this paper. Adding a second polarization is most useful at Lband compared to C-band for winter ice mapping, and for separating thin ice and calm open water based on differences in dielectric properties.

Other frequencies have been suggested in the past, such as X-band (Parashar and others, 1977; Onstott and others, 1979 and 1982; Kim and others, 1984), for better discrimination between FY and MY ice. They have not been considered in this paper because they were not available, and because L- and C-band are the only two frequencies available from space over the polar regions for a number of years to come, and we need to establish clearly the level of performance of these different SAR systems for ice mapping. Our results suggest that 
deformed FY ice plays a critical role in the interpretation of microwave signatures of sea-ice, and in mapping of ice conditions, even in winter when MY and undeformed FY are well separated in radar back-scatter, but that these ambiguities can be resolved by combining complementary long and short wavelengths such as L- and C-band. In transition zones where CFY is present in large quantities, ERS-1 and Radarsat are expected to overestimate the MY ice fraction by $15-20 \%$, but still provide a good representation of the spatial variability of ice thickness, and J-ERS-1 is expected to perform poorly. Simply combining ERS-1 or Radarsat data with J-ERS-1 data would overcome these limitations drastically.

\section{ACKNOWLEDGEMENTS}

The authors undertook this work in the Aircraft Radar Group of the Radar Science and Engineering Section and in the Polar Oceanography Group at the Jet Propulsion Laboratory, California Institute of Technology, under contract to the Oceanic Processes Branch of the U.S. National Aeronautics and Space Administration. The authors wish to thank D. Eppler and D. Farmer for use of the KRMS image data, and T. Wen for providing pictures of the APLIS' 88 camp.

\section{REFERENCES}

Attema, E. P. W. 1991. The active microwave instrument on-board the ERS-1 satellite. Proc. IEEE, 79, 791-799.

Borgeaud, M., R. T. Shin and J. A. Kong. 1987. Theoretical models for polarimetric radar clutter. Foumal of Electromagnetic Waves and Applications, 1(1), 67-86.

Bredow, J.S., S. P. Gogineni, A.J. Gow, P.F. Blanchard and R.K. Moore. 1989. Radar backscattering from artificially grown sea ice. IEEE F. Oceanic Eng., 14(13), 259-264.

Burns, B. A. 1990. SAR image statistics related to atmospheric drag over sea ice. IEEE Trans. Geosci. Remote Sensing, GE-28(2), 158-165.

Carsey, F.D., R. G. Barry and W. F. Weeks. 1992. Introduction. In Carsey, F. D., ed. Microwave remote sensing of sea ice. Washington, DC, American Geophysical Union, 1-7. (Geophysical Monograph 68.)

Cavalieri, D.J. 1992. The validation of geophysical products using multisensor data. In Carsey, F. D., ed. Microwave remote sensing of sea ice. Washington, DC, American Geophysical Union, 233-242. (Geophysical Monograph 68.)

Cavalieri, DJ., B. A. Burns and R. G. Onstott. 1990. Investigation of the effects of summer melt on the calculation of sea ice concentration using active and passive microwave data. 7. Geophys. Res., 95(C4), 5359-5369.

Cavalieri, D.J. and 6 others. 1991. Aircraft active and passive microwave validation of sea ice concentration from the Defense Meteorological Satellite Program Special Sensor Microwave Imager. 7. Geophys. Res., 96(C12), 21,989-22,008.

Drinkwater, M. R. and G. B. Crocker. 1988. Modelling changes in the dielectric and scattering properties of young snow-covered sea ice at GHz frequencies. J. Glaciol., 34(118), 274-282.

Drinkwater, M. R., R. Kwok, D. P. Winebrenner and E. Rignot. 1991. Multi-frequency polarimetric synthetic aperture radar observations of sea ice. F. Geophys. Res., 96(C11), 20,679-20,698.

Drinkwater, M. R., R. Kwok, E. Rignot, H. Israelson, R. Onstott and D. P. Winebrenner. 1992. Potential applications of polarimetry to the classification of sea ice. In Carsey, F. D., ed. Microwave remote sensing of sea ice. Washington, DC, American Geophysical Union, 419-430. (Geophysical Monograph 68.)

Eppler, D. T., L. D. Farmer, A. W. Lohanick and M. Hoover. 1986. Classification of sea ice types with single-band $(33.6 \mathrm{GHz})$ airborne passive microwave imagery. J. Geophys. Res., 91 (C9), 10,661-10,695.
Farmer, L. D., D. T. Eppler and A. W. Lohanick. 1990. Converting digital passive microwave radiances to Kelvin units of brightness temperatures. Stennis Space Center, MS, NORDA. (Technical Note 427.)

Freeman, A. 1990. A calibration and image quality assessment of the NASA/ JPL aircraft SAR during spring 1988. Pasadena, CA, California Institute of Technology. Jet Propulsion Laboratory. (JPL Technical Report D-7197.)

Gray, A.L., R.K. Hawkins, C.E. Livingstone, L.D. Arsenault and W. M. Johnstone. 1982. Simultaneous scatterometer and radiometer measurements of sea-ice microwave signatures. IEEE J. Oceanic Eng., 7, 20-32.

Johansson, R. and J. Askne. 1987. Modelling of radar backscattering from low-salinity ice with ice ridges. Int. F. Remote Sensing, 8(11), $1667-1677$.

Kim, Y.S., R.K. Moore and R.G. Onstott. 1984. Theoretical and experimental study of radar backscatter from sea ice. Lawrence, KS, University of Kansas. Remote Sensing Laboratory. (Technical Report 331-37.)

Kim, Y.S., E. Rodriguez and S. Durden. 1992. A numerical assessment of rough surface scattering theories: vertical polarization. Radio Sci., 27, 515-528.

Kwok, R., E. Rignot, B. Holt and R. G. Onstott. 1992. Identification of sea ice types in spaceborne synthetic aperture radar data. F. Geophys. Res., 97(C2), 2391-2402.

Livingstone, C.E., K.P. Singh and A.L. Gray. 1987. Seasonal and regional variations of active/passive microwave signatures of sea ice. IEEE Trans. Geosci. Remote Sensing, GE-25(2), 159-173.

Lyden, J.D., B. Burns and A. L. Maffet. 1984. Characterization of seaice types using synthetic aperture radar. IEEE Trans. Geosci. Electron., 22(5), 431-439.

Manninen, A.T. 1991. Surface backscattering dependence on various properties of ice ridges. In Putkonen, J., ed. IGARSS '91. Remote sensing: global monitoring for Earth management. 1991 International Geoscience and Remote Sensing Symposium, Helsinki University of Technology, Espoo, Finland, fune 3-6, 1991. Proceedings. Vol. 3. New York, Institute of Electrical and Electronics Engineers, 1219-1226.

Massom, R.A. 1991. Satellite remote sensing of polar regions. London, Belhaven; Boca Raton, FL, Lewis Publishers.

Nemoto, Y., H. Nishino, M. Ono, H. Mizutamari, K. Nishikawa and K. Tanaka. 1991. Japan Earth Resources Satellite-1 synthetic aperture radar. Proc. IEEE, 79, 800-809.

Ngheim, S.V., S.H. Yueh, R. Kwok and F. K. Li. 1992. Symmetry properties in polarimetric remote sensing. Radio Sci., 27, 693-712.

Oh, Y., K. Sarabandi and F. T. Ulaby. 1992. An empirical model and an inversion technique for radar scattering from bare soil surfaces. IEEE Trans. Geosci. Remote Sensing, GE-30(2), 370-381.

Onstott, R.G. 1992. SAR and scatterometer signatures of sea ice. In Carsey, F. D., ed. Microwave remote sensing of sea ice. Washington, DC, American Geophysical Union, 73-102. (Geophysical Monograph 68.)

Onstott, R.G. and S. Gogineni. 1985. Active microwave measurements of Arctic sea ice under summer conditions. F. Geophys. Res., 90 (C3), 5035-5044.

Onstott, R. G., R. K. Moore and W.F. Weeks. 1979. Surface-based scatterometer results of Arctic sea ice. IEEE Trans. Geosci. Electron., 17(3), 78-85.

Onstott, R. G., R. K. Moore, S. Gogineni and C. V. Delker. 1982. Four years of low-altitude sea ice broadband backscatter measurements. IEEE 7. Oceanic Eng., 7(1), 44-50.

Onstott, R.G., T. C. Grenfell, C. Mätzler, C.A. Luther and E.A. Svendsen. 1987. Evolution of microwave sea ice signatures during early summer and midsummer in the marginal ice zones. F. Geophys. Res., 92(C7), 6825-6835.

Parashar, S. K. 1974. Investigation of radar discrimination of sea ice. (Ph.D. dissertation, University of Kansas.)

Parashar, S. K., R. M. Haralick, R. K. Moore and A.W. Biggs. 1977. Radar scatterometer discrimination of sea ice types. IEEE Trans. Geosci. Electron., 15(2), 83-87.

Raney, R. K., A.P. Luscombe, E.J. Langham and S. Ahmed. 1991. Radarsat. Proc. IEEE, 79, 827-838.

Rice, S.O. 1951. Reflection of electromagnetic waves from slightly rough surfaces. Commun. Pure Appl. Math., 4, 351-378.

Rignot, E. and R. Chellappa. 1991. Segmentation of complex synthetic aperture radar data. F. Opt. Soc. Am., A8, 1499-1511.

Rignot, E. and R. Chellappa. 1992. Segmentation of polarimetric SAR data. IEEE Trans. Image Processing, 1, 281-300.

Rignot, E. and R. Kwok. 1993. Characterization of spatial statistics of distributed targets in SAR data. Int. F. Remote Sensing, 14, 345-366. 
Rignot, E., R. Chellappa and P. Dubois. 1992. Unsupervised segmentation of polarimetric SAR data using the covariance matrix. IEEE Trans. Geosci. Remote Sensing, GE-30(4), 687-705.

Rothrock, D.A. 1992. Ice thickness observations from satellites. In Thorndike, A. S., C. Parkinson and D. A. Rothrock, eds. Report of the Sea Ice Thickness Workshop, 19-21 November, 1991, New Carrollton, Maryland. Seattle, WA, University of Washington. Applied Physics Laboratory, B60-B64.

Steffen, K. and 6 others. 1992. The estimation of geophysical parameters using passive microwave algorithms. In Carsey, F. D., ed. Microwave remote sensing of sea ice. Washington, DC, American Geophysical Union, 233-242. (Geophysical Monograph 68.)

Stogryn, A. and G.J. Desargent. 1985. The dielectric properties of brine in sea ice at microwave frequencies. IEEE Trans. Antennas Propagat., 33(5), 523-532.

Ulaby, F.T. and C. Elachi. 1990. Radar polarimetry for geoscience applications. Norwood, MA, Artech House.

Ulaby, F. T., R. K. Moore and A. K. Fung. 1986. Microwave remote sensing: active and passive. Volume III. Norwood, MA, Artech House.

Van de Hulst, H. C. 1981. Light scattering by small particles. New York, Dover.

Van Zyl, J.J. 1990. Calibration of polarimetric radar images using only image parameters and trihedral corner reflector responses. IEEE Trans. Geosci. Remote Sensing, GE-28(3), 337-348.
Vant, M.R., R.B. Gray, R.O. Ramseier and V. Makios. 1974. Dielectric properties of fresh and sea ice at 10 and $35 \mathrm{GHz} . \mathcal{F}$. Appl. Phys., 45(11), 4712-4717.

Vant, M. R., R. O. Ramseier and V. Makios. 1978. The complex dielectric constant of sea ice at frequencies in the range $01 .-40 \mathrm{GHz}$. J. Appl. Phys., 49(3), 1264-1280.

Weeks, W.F. and S.F. Ackley. 1982. The growth, structure and properties of sea ice. CRREL Monogr. 82-1.

Wen, T., W.J. Felton, J. C. Luby, W. L. Fox and K. L. Kientz. 1989. Environmental measurements in the Beaufort Sea, spring 1988. Seattle, WA, University of Washington. Applied Physics Laboratory. (Technical Report APL-UW TR 8822.)

Winebrenner, D. P., L. Tsang, B. Wen and R. West. 1989. Sea-ice characterization measurements needed for testing of microwave remote sensing models. IEEE J. Oceanic Eng., 14(2), 147-157.

Winebrenner, D.P. and 14 others. 1992. Microwave sea ice signature modeling. In Carsey, F.D., ed. Microwave remote sensing of sea ice. Washington, DC, American Geophysical Union, 137-175. (Geophysical Monograph 68.)

The accuracy of references in the text and in this list is the responsibility of the authors, to whom queries should be addressed.

MS received 22 March 1993 and in revised form 15 fuly 1993 